\title{
Gall bladder perforation along the abdominal wall: An unusual picture
}

\author{
Anil Kumar Singh ${ }^{1}$, Archna Gupta ${ }^{2}$ \\ From ${ }^{1}$ Assistant Professor, ${ }^{2}$ Professor, Department of Radiodiagnosis, Sanjay Gandhi Postgraduate Institute of Medical Sciences, Lucknow, \\ Uttar Pradesh, India
}

$\mathrm{W}$ e are presenting images from the computed tomography (CT) Abdomen study of a middle-aged adult male patient who was admitted to the intensive care facility due to severe pneumonitis, sepsis, and chronic renal failure (on dialysis). In view of abdominal distension and tenderness, bedside ultrasound of the abdomen was done. Ultrasound revealed cholelithiasis with overdistended gall bladder (GB), ascites, and suspicious loculation of perihepatic fluid, among various other findings. Keeping in mind the clinical picture and ultrasound findings, the possibility of GB perforation (GBP) and peritonitis was suspected. Contrast-enhanced CT (CECT) of the abdomen was done for further evaluation. CECT of the abdomen revealed overdistended GB $(\sim 10.0 \times 6.0 \times 5.1 \mathrm{~cm})$ with a small focal mural defect in the fundus region. This defect was found to be contiguous with a tract along the inner surface of the anterior abdominal wall, with tract inferiorly communicating with a localized fluid collection $(\sim 6.0 \times 3.8 \times 8.2 \mathrm{~cm})$. The fluid collection was also noted along the inner surface of the anterior abdominal wall (fascia transversalis) and bulging into the omentum. Collection was localized and thin-walled (Figs. 1a-h and $2 \mathrm{a}$ and $\mathrm{b}$ ). This GBP was considered as type-2 as it was not communicating with other hollow viscera, and also there was no evidence of direct communication with the peritoneal cavity. Had it been a free peritoneal rupture, GB would not have been overdistended. Tract form GB fundus beneath the abdominal wall was collapsed/likely sealed near GB fundus which might explain the overdistended status of the GB. "The appearance of this perforation was like dissecting along the inner surface of the anterior abdominal wall and then forming a localized collection".

GBP was classified into three types by Niemeier and revised later. These three types are as - Type 1 (acute): rupture into peritoneal cavity leading to biliary peritonitis; Type 2 (subacute): localized rupture with pericholecystic abscess, intrahepatic, focal omental, or abdominal wall extension. Type-3 (chronic form): formation of the fistulous tract between the GB and another hollow viscus or skin/exterior [1-3]. In the case presented here, though there was a tract extending from GB fundus, this tract

\section{Access this article online}

Received - 20 September 2021

Initial Review - 16 October 2021

Accepted - 10 October 2021

DOI: $10.32677 /$ ijcr.v7i10.3087

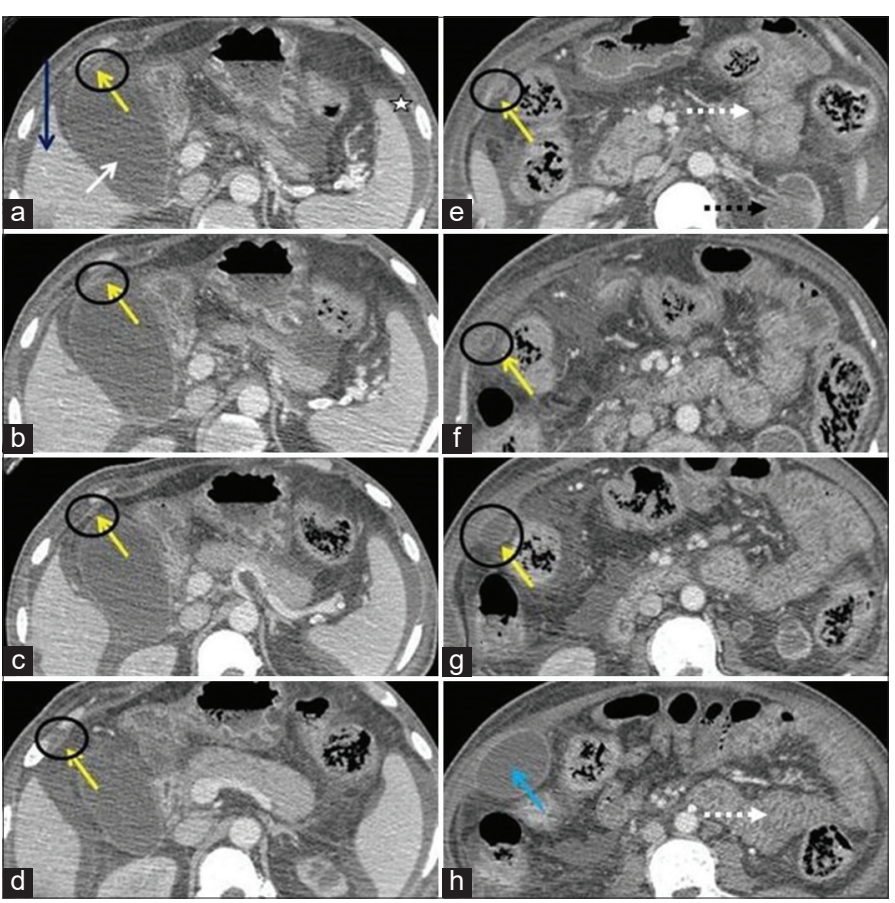

Figure 1: (a-h) Axial Contrast-enhanced computed tomography images form upper to mid-abdomen region showing a tract (yellow arrows and encircled) extending from fundus of overdistended Gall Bladder (white arrow, a) to localized collection (light blue arrow, h) along inner surface of right anterior abdominal wall. Small focal defect mural defect in GB fundus (encircled in a). Ascites (white asterisk, a) bowel wall edema (white dashed arrows, e and h) and hydronephrotic left kidney (black dashed arrow, e) and also noted. (Dark Blue Arrow: Liver)

was leading to a localized walled-off collection along the inner aspect of the anterior abdominal wall and not communicating with another hollow viscus or exterior; hence, this perforation should be considered as type-2. Such perforations can be difficult to visualize on ultrasound. CT images, especially a combination of axial images and multiplanar reformats possible with the currently available generation of multi-slice CT systems, can readily confirm such perforations.

On ultrasound, small mural defects in the GB wall may be missed, and it may reveal only findings such as overdistended GB, mural thickening, and pericholecystic edema features overlapping with cholecystitis. However, large defects are

Correspondence to: Anil Kumar Singh, Department of Radiodiagnosis, Sanjay Gandhi Postgraduate Institute of Medical Sciences, Lucknow - 226014 , Uttar Pradesh, India. E-mail: singh.anil.kr01@gmail.com

(C) 2021 Creative Commons Attribution-NonCommercial 4.0 International License (CC BY-NC-ND 4.0). 


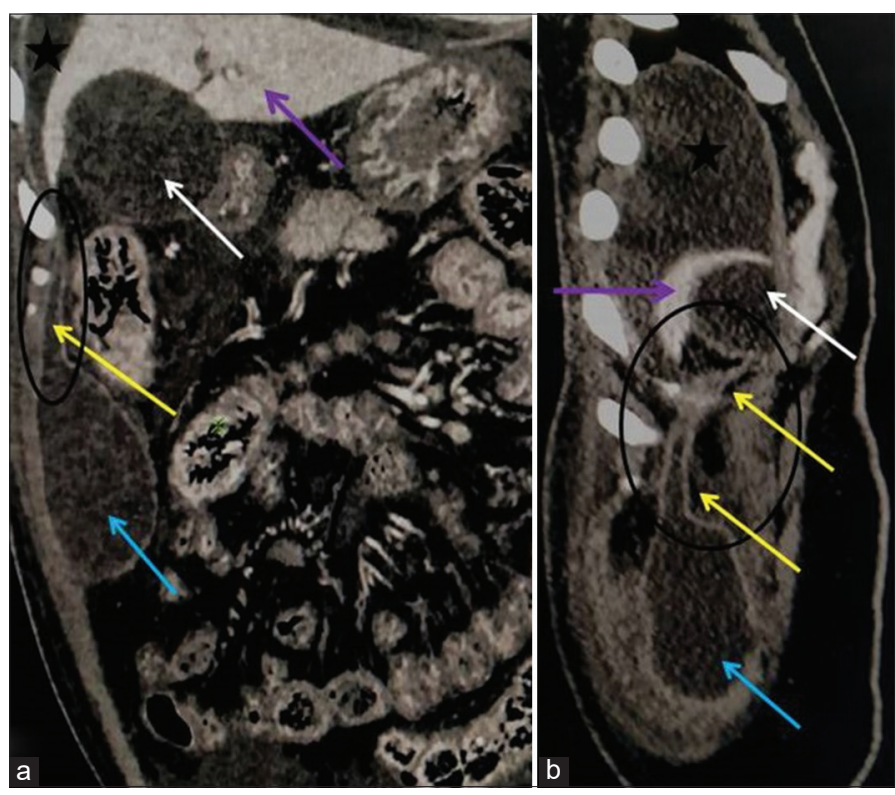

Figure 2: (a and b) Coronal (a) and oblique sagittal (b) reformatted computed tomography images showing overdistended Gall Bladder (GB) (white arrow) and a fluid collection along inner aspect of anterolateral abdominal wall (light blue arrow): superiorly a tract (yellow arrows) is noted extending from collection to GB. Entire tract is visualized on oblique sagittal image (b). (Dark Blue Arrow: Liver; Black Asterisk: Ascites)

usually not missed. Calculi are easily depicted on ultrasound. On ultrasound, if there is a pericholecystic collection or intrahepatic collection adjoining GB fossa, GBP needs to be suspected even if the defect is not obvious. In such cases, further evaluation with CECT or Magnetic Resonance Imaging (MRI) is needed. Mural defects are readily visualized on CECT and MRI, as are mural thickening, accompanying collections/abscess, and inflammatory changes. Intramural air, which can be seen in emphysematous cholecystitis, is best visualized on CT [2-5]. CT, especially multislice CT, has been found to be the most accurate and sensitive imaging modality to detect GB perforations [5].

\section{REFERENCES}

1. Date RS, Thrumurthy SG, Whiteside S, Umer MA, Pursnani KG, Ward JB, et al. Gallbladder perforation: Case series and systematic review. Int J Surg 2012;10:63-8.

2. Derici H, Kara C, Bozdag AD, Nazli O, Tansug T, Akca E. Diagnosis and treatment of gallbladder perforation. World J Gastroenterol 2006;12:7832-6.

3. Patel NB, Oto A, Thomas S. Multidetector CT of emergent biliary pathologic conditions. Radiographics 2013;33:1867-88.

4. Harraz MM, Abouissa AA. Role of MSCT in the diagnosis of perforated gall bladder (a retrospective study). Egypt J Radiol Nuclear Med 2020;51:4.

5. Hollanda ES, Torres UD, Gual F, Oliveira EP, Cardoso LV, Criado DA. Spontaneous perforation of gallbladder with intrahepatic biloma formation: Sonographic signs and correlation with computed tomography. Radiol Bras 2013;46:320-2

Funding: None; Conflict of Interest: None Stated.

How to cite this article: Singh AK, Gupta A. Gall bladder perforation along the abdominal wall: An unusual picture. Indian J Case Reports. 2021;7(10):465-466. 